\title{
PELATIHAN DAN PENERAPAN SISTEM PRESENSI BERBASIS KOMPUTER UNTUK PENGELOLAAN DATA KEHADIRAN APARAT DESA
}

\author{
Rohmat Gunawan*, Alam Rahmatulloh \\ Jurusan Informatika, Fakultas Teknik, Universitas Siliwangi \\ e-mail: rohmatgunawan@unsil.ac.id
}

\begin{abstract}
The village as a government system that has territorial boundaries, has the authority to regulate and manage government affairs, is required to provide optimal services to the community. Managing village attendance data must be managed properly, because it can affect the performance of services to the community. The conventional recording of attendance data is usually done when the hours come to work by putting a signature on a book or attendance form. The process of recording attendance like this is very simple but easily manipulated. The purpose of this community service activity is to deal with deficiencies that occur in the process of recording conventional attendance data. In this dedication activity, a computer-based attendance recording system is implemented using the fingerprint time attendance tool. Compared to other electronic based attendance records, such as: time recording machine, ID card with barcode system, magnetic card and RFID card, this fingerprint based attendance recording system has a better performance, because the process of taking attendance data is based on the fingerprint pattern of each apparatus village, so that the safeguarding of identity to others can be minimized. As a result of this dedication activity, a fingerprint-based attendance data recording system has been implemented, training in the use of the system to administrators managing attendance data at partner locations has been carried out and attendance data reports are automatically processed by the system and can be displayed or printed when needed.
\end{abstract}

Keywords: computers, fingerprints, presence, village officials

\begin{abstract}
Abstrak
Desa sebagai suatu sistem pemerintahan yang memiliki batas wilayah, berwenang mengatur dan mengurus urusan pemerintahan, dituntut untuk memberikan pelayanan optimal kepada masyarakat. Pengelolaan data kehadiran aparat desa harus dikelola dengan baik, karena dapat mempengaruhi kinerja pelayanan kepada masyarakat. Pencatatan data kehadiran secara konvensional, biasanya dilakukan ketika jam masuk kerja dengan membubuhkan tanda tangan pada sebuah buku atau form daftar hadir. Proses pencatatan kehadiran seperti ini sangat sederhana tetapi mudah dimanipulasi. Tujuan dari kegiatan pengabdian ini, untuk menangani kekurangan yang terjadi pada proses pencatatan data kehadiran konvensional. Dalam kegiatan pengabdian ini, diterapkan sistem pencatatan kehadiran berbasis komputer dengan menggunakan alat bantu fingerprint time attendance. Dibanding dengan pencatatan kehadiran berbasis elektronik lainnya, seperti: time recording machine, id card with barcode system, magnetic card dan RFID card, sistem pencatatan kehadiran berbasis fingerprint ini mempunyai kinerja yang lebih baik, karena proses pengambilan data kehadiran didasarkan pada pola sidik jari setiap aparat desa, sehingga penitipan identitas kepada orang lain dapat diminimalisir. Hasil dari kegiatan pengabdian ini, telah diterapkannya sistem pencatatan data kehadiran berbasis fingerprint, pelatihan penggunaan sistem kepada administrator pengelola data kehadiran di lokasi mitra telah dilakukan dan laporan data kehadiran secara otomatis diproses oleh sistem serta dapat ditampilkan atau dicetak ketika dibutuhkan.
\end{abstract}

Kata Kunci : aparat desa, komputer, presensi, sidik jari 


\section{PENDAHULUAN}

Kinerja aparat desa harus terus ditingkatkan guna memberikan pelayanan yang lebih baik kepada masyarakat. Aktifitas kerja aparat desa dipengaruhi oleh tingkat kehadiran dan kedisiplinan terhadap jadwal dan jam kerja (Rahmatulloh \& Gunawan, 2019). Proses pencatatan data kehadiran aparat desa perlu dikelola dengan baik, karena mempengaruhi kinerja pelayanan kepada masyarakat (Rianto \& Gunawan, 2017). Pencatatan data kehadiran secara tradisional, biasanya dilakukan dengan membubuhkan tanda tangan pada sebuah buku atau form daftar hadir pada jam masuk kerja. Proses pencatatan seperti ini sangat sederhana dan mudah diimplementasikan, tetapi mudah dimanipulasi.

Beberapa alternatif solusi pencatatan data kehadiran dengan bantuan alat elektronik pernah dilakukan pada penelitian sebelumnya, diantaranya: sistem kehadiran menggunakan kartu berbasis Radio frequency identification (RFId) (Panggabean \& Pandi, 2013), (Setiawan \& Kurniawan, 2015), sistem presensi menggunakan kartu berbasis $Q R$ Code (Nuddin \& Fithri, 2015), (Aini, Rahardja, \& Fatillah, 2018), (Setyorini \& Arifin, 2018), sistem kehadiran berbasis kartu dengan menggunakan barcode (Fadlil, Firdausy, \& Hermawan, 2008), (Nasution, 2010). Meskipun sudah menggunakan alat bantu elektronik, namun masih memungkinkan terjadinya penyalahgunaan, diantaranya dengan cara menitipkan kartu identitas yang digunakan untuk pencatatan data kehadiran kepada orang lain. Sehingga walaupun orang yang bersangkutan tidak hadir, tetapi catatan kehadirannya tetap ada. Hal ini merupakan suatu tindakan pelanggaran berkaitan dengan kedisiplinan kerja.

Agar identitas tidak mudah untuk dipalsukan pada saat proses pencatatan data kehadiran, maka pencatatan data kehadiran berbasis biometrik merupakan salah satu solusi yang dapat diterapkan.

Sistem pencatatan kehadiran berbasis biometrik dilakukan dengan cara mengenali seseorang berdasarkan pola fisik yang dimiliki, seperti: pola sidik jari (Larasatri, 2016), (Sinaga \& Tamba, 2019), (Rozikin \& Purwantini, 2014), pola wajah (Widodo, Sunardi, \& Fadlil, 2019), (P \& Subkhiana, 2016), pola suara (Widodo et al., 2019), (Widodo, Sunardi, \& Fadlil, 2018) atau pola iris mata (Shabrina, Isnanto, \& Hidayatno, 2013).

Saat ini mekanisme biometrik umum digunakan dan paling aman karena penggunaan otentikasi langsung kepada pengguna dan tidak mudah dimanipulasi. Meskipun demikian, sistem biometrik dipengaruhi oleh intensitas cahaya, kualitas gambar dan distorsi dalam gambar. Teknologi biometrik menjadi dasar dari berbagai solusi identifikasi dan verifikasi pribadi yang aman, serta mekanisme otentikasi yang dapat diandalkan.

Otentikasi pola sidik jari merupakan salah satu implementasi dari teknologi biometrik yang unggul dibandingkan otentikasi indentitas fisik lainnya. Selain dari itu, otentikasi pola sidik jari (fingerprint) juga merupakan salah satu tekologi biometrik yang paling banyak digunakan dengan tingkat penerimaan yang cukup baik. Pencatatan data kehadiran berbasis fingerprint merupakan salah satu implementasi dari sistem biometrik dengan menggunakan pola sidik jari. Sistem presensi ini sudah umum diterapkan bahkan dapat diintgrasikan dengan sistem lainnya, misalanya dengan menggunakan teknologi Web Service (Rahmatulloh, Gunawan, \& Darmawan, 2019).Berdasarkan latar belakang tersebut dalam kegiatan pengabdian ini diterapakan sistem kehadiran berbasis komputer dengan bantuan fingerprint time attendance (alat pencatat kehadiran berbasis sidik jari). 


\section{METODE PENGABDIAN}

Terdapat beberapa aktivitas yang dilakukan pada kegiatan pengabdian ini. Secara umum terdapat tiga tahapan yang dilakukan: persiapan, pelaksanaan, penutup. Berikut aktivitas yang dilakukan dari setiap tahapan kegiatan:

\section{A. Persiapan}

1. Pada tahap ini dilakukan kunjungan awal ke lokasi mitra pengabdian (Desa Sukarame Kecamatan Sukaresik dan Desa Sukaresik Kecamatan Sukaresik Kabupaten Tasikmalaya Jawa Barat)

2. Pengumpulan data terdiri dari: pengumpulan data kehadiran yang berjalan sekarang, aturan jam kerja, pengumpulan data aparat desa.

3. Pengumpulan informasi laporan rekapitulasi kehadiran setiap bulan.

4. Masalah-masalah yang dihadapi dalam ruang lingkup pengolahan data kehadiran yang sekarang berjalan.

\section{B. Pelaksanaan}

1. Pemasangan perangkat Fingerprint Time Attendace di lokasi mitra pengabdian

2. Input data aparat, pengaturan jam kerja, pengaturan jam kerja sesuai aturan jam kerja yang belaku di lokasi mitra pengabdian

3. Pelatihan penggunaan perangkat (pengenalan fitur aplikasi).

4. Uji coba pembuatan laporan daftar hadir.

\section{Penutup}

1. Peninjauan ulang penggunaan perangkat ke lokasi mitra pengabdian

2. Uji coba cetak laporan daftar hadir setelah periode tertentu di lokasi mitra pengabdian

\section{HASIL DAN PEMBAHASAN}

Secara umum terdapat beberapa tahap yang dilakukan pada kegiatan pengabdian ini seperti ditampilkan pada Gambar 1.

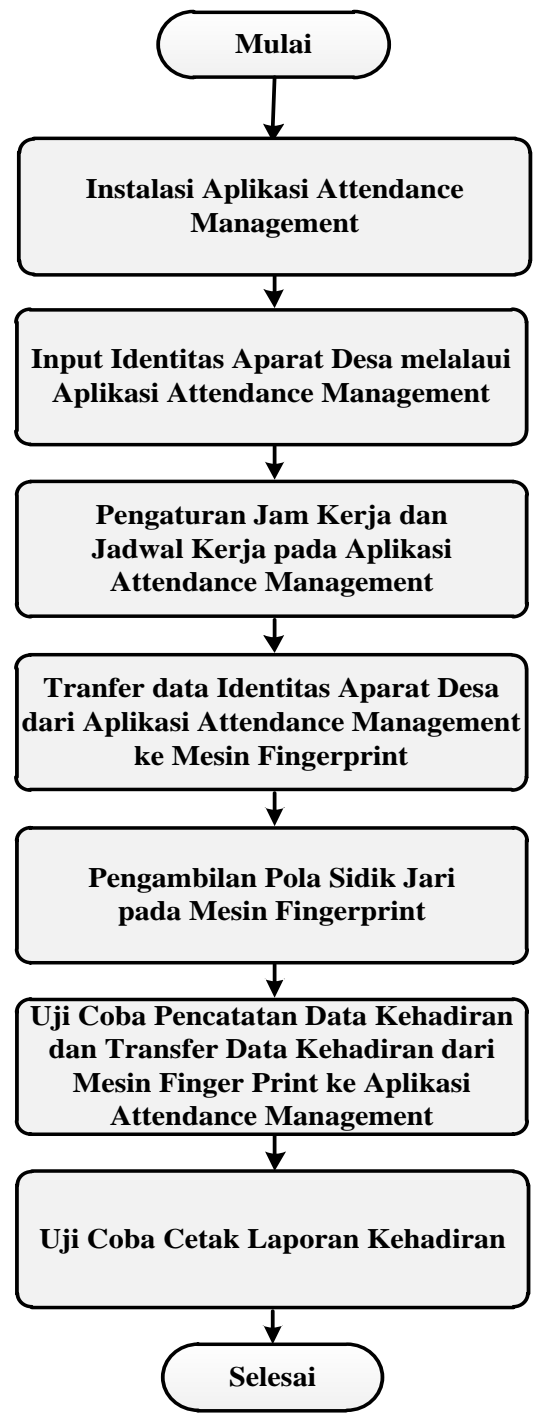

Gambar 1. Tahapan Pelaksanaan Pengabdian

\section{Instalasi Aplikasi Attendance Management.}

Tahap pertama pada kegiatan pengabdian ini yaitu melakukan installasi aplikasi Attendance Management. Instalasi dilakukan pada komputer di lokasi mitra, yang selanjutnya akan digunakan untuk mengolah data kehadiran berbasis fingerprint seperti ditampilkan pada gambar 2. 


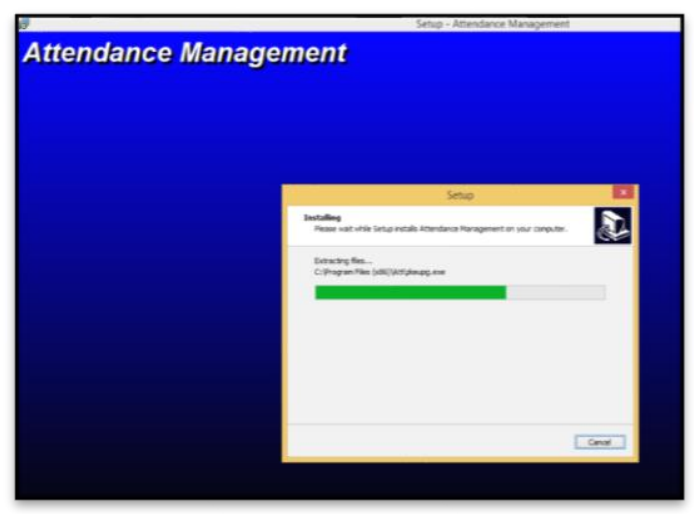

Gambar 2. Istalasi aplikasi Attendance Management

2. Input Identitas Aparat Desa Melalui Aplikasi Attendance Management.

Pada tahap ini dilakukan input data setiap aparat desa ke dalam sistem. Data yang diinputkan diantaranya: Nama, Tempat Tanggal Lahir, Jenis Kelamin, Jabatan, Alamat.

3. Pengaturan Jam Kerja dan Jadwal Kerja pada Aplikasi Attendance Management.

Pada tahap ini dilakukan pengaturan jam kerja dan jadwal kerja sesuai aturan berlaku di kantor desa mitra seperti ditampilkan pada gambar 3 .

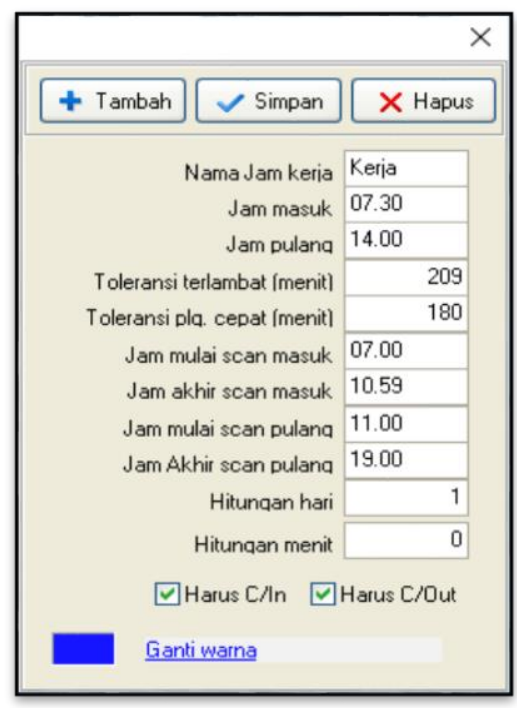

Gambar 3. Tampilan menu pengaturan jam kerja pada aplikasi Attendance Management
4. Transfer data Identitas Aparat Desa dari Aplikasi Attendace Mangement ke Mesin Fingerprint.

Data aparat desa yang telah tersimpan di database pada aplikasi Attendance Management, selanjutnya ditransfer ke mesin fingerprint seperti ditampilkan pada gambar 4.

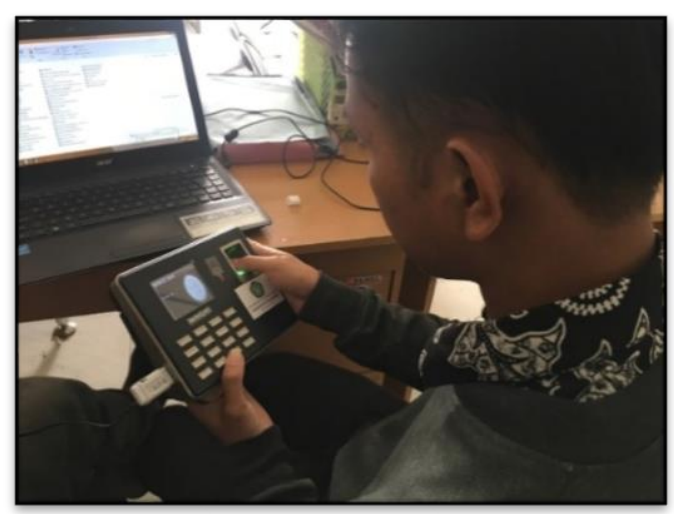

Gambar 4. Transfer Data ke Mesin Finger Print

5. Pengambilan Pola Sidik Jari pada Mesin Finger Print.

Pada tahap ini dilakukan pengambilan pola sidik jari setiap aparat desa, agar setiap aparat dapat menggunakan sistem presensi berbasis fingerprint. Pengambilan pola sidik jari disesuaikan dengan identitas setiap aparat yang telah tersimpan pada mesin fingerprint seperti ditampilkan pada gambar 5 . Gambar 5. Pengambilan Pola Sidik Jari

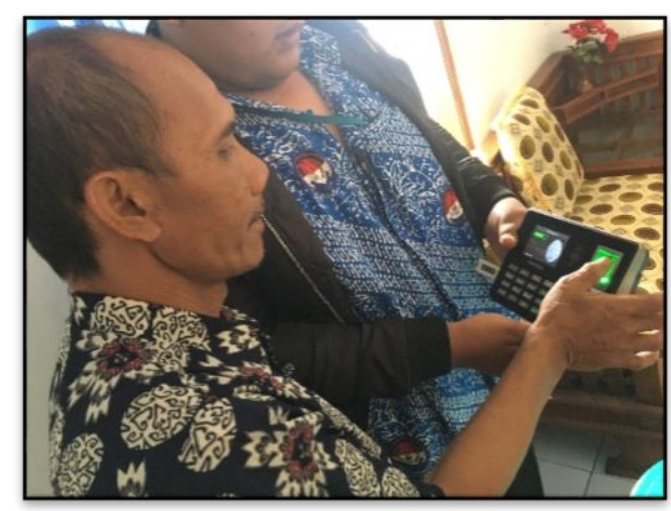

Aparat Desa

6. Uji Coba Pencatatan Data Kehadiran dan Transfer Data Kehadiran dari Mesin Fingerprint ke Aplikasi Attendance Mangement. 
Setiap dilakukan pencatatan pola sidik jari pada saat proses presensi, maka data prsesensi akan tersimpan pada mesin fingerprint. Agar dapat diolah menjadi laporan kehadiran, maka pada tahap ini dilakukan transfer data presensi dari mesin finger print ke aplikasi Attendance Management.

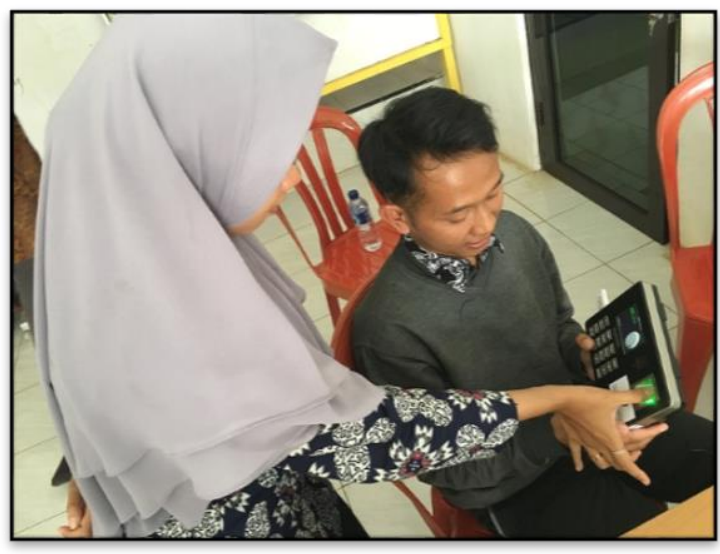

Gambar 6. Uji Coba Pencatatan Data Kehadiran Pada Mesin Finger Print

\section{Uji Coba Cetak Laporan Kehadiran}

Pada tahap ini dilakukan uji coba cetak laporan data kehadiran aparat desa.

Setelah setiap tahapan selesai dikerjakan, langkah berikutnya melakukan pelatihan kepada aparat desa yang selanjutnya menjadi administrator atau pengelola sistem presensi berbasis fingerprint. Kemudian pada akhir kegiatan dilakukan serah terima perangkat mesin fingerprint kepada mitra, seperti ditampilkan pada gambar 7 .

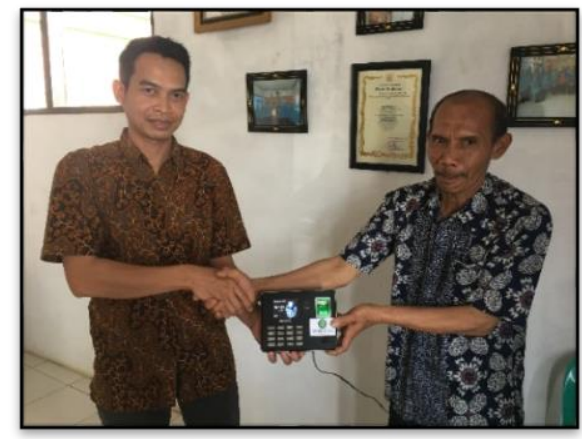

Gambar 7. Serah Terima Mesin fingerprint
Kegiatan pengabdian diakhiri dengan foto bersama antara Tim Pelaksana Pengabdian dan aparat desa mitra seperti ditampilkan pada gambar 8 .

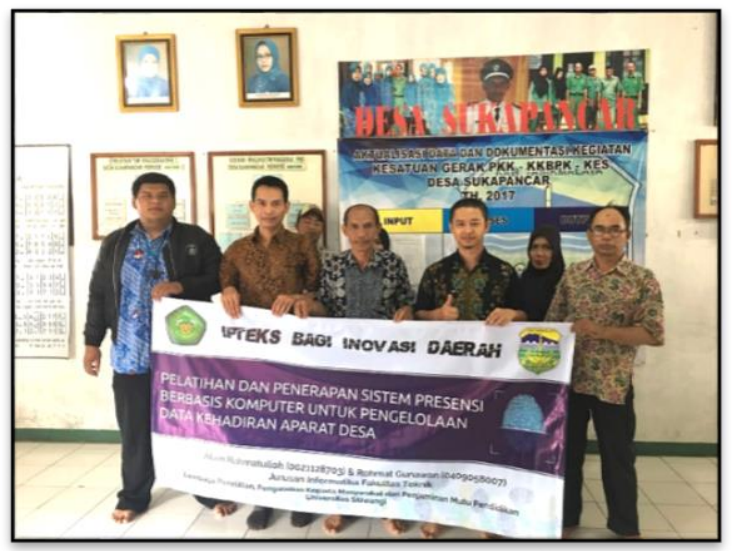

Gambar 8. Foto bersama aparat desa

\section{SIMPULAN}

1. Penerapan sistem presensi berbasis komputer dengan menggunakan Fingerprint Time Attendance yang telah dilakukan di lokasi mitra pengabdian dapat mengurangi penyalahgunaan tanda tangan yang masih terjadi pada sistem pencatatan kehadiran konvesional.

2. Sistem pelaporan data kehadiran secara otomatis diproses oleh sistem, dan dapat ditampilkan atau dicetak ketika dibutuhkan.

\section{UCAPAN TERIMA KASIH}

Syukur kami panjatkan kepada Allah SWT karena atas ridha-Nya kegiatan pengabdian ini dapat terlaksana. Tidak lupa kami sampaikan ucapan terima kasih yang sebesar-besarnya kepada:

1. LP2M-PMP Universitas Siliwangi yang telah mendukung dan memberikan dana kegiatan.

2. Pemerintah Desa Sukarame Kecamatan Sukaresik dan Desa Sukaresik Kecamatan Sukaresik Kabupaten Tasikmalaya Jawa Barat yang telah menjadi mitra pada kegiatan pengabdian ini.

3. Rekan-rekan Dosen Progarma Studi Informatika Fakultas Teknik Universitas Siliwangi. 


\section{DAFTAR PUSTAKA}

[1] Aini, Q., Rahardja, U., \& Fatillah, A. (2018). Penerapan Qrcode Sebagai Media Pelayanan Untuk Absensi Pada Website Berbasis Php Native. Sisfotenika, $\quad 8(1), \quad 47$. https://doi.org/10.30700/jst.v8i1.151

[2] Fadlil, A., Firdausy, K., \& Hermawan, F. (2008). Pengembangan Sistem Basis Data Presensi Perkuliahan Dengan Kartu Mahasiswa Ber-Barcode. TELKOMNIKA (Telecommunication Computing Electronics and Control), 6(1), 65. https://doi.org/10.12928/telkomnika.v $6 \mathrm{i} 1.552$

[3] Larasatri. (2016). Korelasi Implementasi Sistem Presensi Sidik Jari (Fingerprint) Online dan Kedisiplinan Terhadap Perubahan Perilaku Kerja Pegawai. 4(1), 1-20.

[4] Nasution, S. (2010). Sistem Manajemen Administrasi Dan Presensi Online Untuk Perkuliahan Dan Praktikum Menggunakan Oracle. Seminar, 2010(Snati), 123-127. Retrieved from http://journal.uii.ac.id/index.php/Snati/ article/download/1876/1654

[5] Nuddin, M. T., \& Fithri, D. L. (2015). Sistem Absensi Asisten Dosen Menggunakan Qr Code Scanner Berbasis Android Pada Program Studi Sistem Informasi Universitas Muria Kudus. Prosiding SNATIF, O(0), 303310.

[6] P, A. B. W., \& Subkhiana, E. (2016). Ekstraksi Ciri Entropy Untuk Pengenalan Pola Wajah Menggunakan Fuzzy Rule Base. 2(2), 35-42.

[7] Panggabean, V. O., \& Pandi, F. (2013). Sistem Absensi Berbasis Radio Frequency Identification ( RFID ) Pada Mikroskil. JSM STMIK Mikroskil, 14(2), 129-138.
[8] Rahmatulloh, A., \& Gunawan, R. (2019). Sistem Presensi Berbasis Sidik Jari untuk Peningkatan Disiplin Kehadiran Aparat Desa. Jati Emas (Jurnal Aplikasi Teknik Dan Pengabdian Masyarakat), 3(1), 14-18.

[9] Rahmatulloh, A., Gunawan, R., \& Darmawan, I. (2019). Web Services to Overcome Interoperability in Fingerprint-based Attendance System. 2(IcoIESE 2018), 277-282. https://doi.org/10.2991/icoiese18.2019 .49

[10]Rianto, R., \& Gunawan, R. (2017). ITGbM Pelatihan dan Penerapan Finger Print Time Attendance. 3, 253258.

[11] Rozikin, K., \& Purwantini, K. (2014). Pengaruh sistem presensi dengan deteksi sidik jari dan SMS gateway terhadap tingkat membolos siswa. Jurnal Seminar Nasional Teknologi Informasi \& Komunikasi Terapan 2014(Semantik 2014), 2014(November), 60-66.

[12] Setiawan, E. B., \& Kurniawan, B. (2015). perancangan sistem absensi kehadiran perkuliahan radio frequency indentifications (RFId). Jurnal CoreIT,Vol.1,No.2, Desember 2015, 1(2), 44-49.

[13] Setyorini, S., \& Arifin, J. (2018). Pemanfaatan Qr Code Untuk Perekaman Data Kehadiran Siswa Terintegrasi Dengan Sistem Informasi Manajemen Sekolah Smk Mahardika Malang. Network Engineering Research Operation, 4(1), 5-13. https://doi.org/10.21107/nero.v4i1.106

[14] Shabrina, M., Isnanto, R. R., \& Hidayatno, A. (2013). Pengenalan iris mata menggunakan metode analisis komponen utama (principal component analysis -PCA) dan jaringan saraf tiruan perambatan balik. Transient, Vol.2, No. 2, Juni 2013, 
ISSN : 2550-0198

Issn: 2302-9927, 371, 1-5.

[15] Sinaga, T., \& Tamba, T. (2019). Sistem

Presensi Dengan Metode Sidik Jari

Menggunakan Sensor Fingerprint

dengan Tampilan Pada PC. Critical

Care Medicine, 47, 763.

https://doi.org/10.1097/01.ccm.00005

52317.95426.b4

[16] Widodo, Y. F., Sunardi, S., \& Fadlil,

A. (2018). Perancangan Sistem Absensi Kehadiran Karyawan Berdasarkan Verifikasi Ucapan. 134137.

[17] Widodo, Y. F., Sunardi, S., \& Fadlil, A. (2019). Identifikasi Suara Pada Sistem Presensi Karyawan Dengan Metode Ekstraksi MFCC. J-SAKTI (Jurnal Sains Komputer Dan Informatika), 3(1), 115. https://doi.org/10.30645/jsakti.v3i1.107 